\title{
Automatic smoke detection system with favoriot platform using internet of things (IoT)
}

\author{
Mohd Alif bin Suparman, Siat Ling Jong \\ Wireless and Radio Science Centre, Faculty of Electrical and Electronic Engineering, \\ University Tun Hussein Onn Malaysia, Malaysia
}

\begin{tabular}{l}
\hline Article Info \\
\hline Article history: \\
Received Sept 21, 2018 \\
Revised Mar 1, 2019 \\
Accepted Mar 29, 2019 \\
\hline
\end{tabular}

\section{Keywords:}

Arduino uno

Favoriot platform

MQ-2 sensor

Smoke detector

\begin{abstract}
The available fire alarm system in the market unable to inform occupant that their house is on fire. The occupant remains unknown especially when they are away from their house. Most of the time, the house or building almost destroyed by fire when firefighter comes to the scene due to late inform to Fire and Rescue Department. To this aim, automatic smoke detection system using Internet of Things (IoT) is proposed. The proposed system not only able to monitor the smoke condition of a room but also able to alert user and Fire and Rescue Department when certain level of smoke is detected by a gas sensor via Favoriot platform. Arduino Uno is used in this work to control all the devices and WiFi shield acts as a medium to interconnect devices with the network so that the data from the smoke sensor can be read in the Favoriot platform. In this experiment, the condition of room is tested under several burning materials and the smoke levels are recorded. It is found that when the smoke level more than $100 \mathrm{ppm}$, it may cause to sore eyes, cough and hard breathing that can bring to death. Therefore, the best threshold level of the automatic smoke detection system is at $80 \mathrm{ppm}$. By using this system, the user able to take preliminary rescue action to save people and prevent fire breaks out.

Copyright $(2019$ Institute of Advanced Engineering and Science. All rights reserved.
\end{abstract}

\section{Corresponding Author:}

Siat Ling Jong,

Wireless and Radio Science Centre,

Faculty of Electrical and Electronic Engineering,

University Tun Hussein Onn Malaysia,

86400 Batu Pahat, Johor, Malaysia.

Email: sljong@uthm.edu.my

\section{INTRODUCTION}

Automatic fire alarm system is a system designed to rapidly detect fires and notify occupant that the building was on fire [1]. Frequently, a devastating fire occurs accidentally from a flammable source and rapidly spreading from a small area to whole building [2]. Therefore, the fire alarm system has been in use since the Great Fire of London in 1667 [3]. There are variety of fire alarm systems available in the market such as smoke and heat detector that are able to operate automatically on detecting a fire [4]. Automatic sprinkler that based on water-based fire supression systems is another commonly used fire proctection system in high-rise buildings, shoplot and factories but not residential house [5]. The sprinkler will release water when the detector senses any smoke and heat over the threshold value. The fire alarm system will be activated once the fire is detected. There are few types of automatic sprinklers that suit for different application. The details on the type of sprinklers can be found in [6]. Nowaday, fire alarm systems have become increasingly sophisticated and functionally more capable and reliable [7]. The previous research shows the new trend to detect fire disaster by using a real-time video imaging process based on red, green and blue color model to identify a real fire occurrence by capturing data and analyzed in computer [8]. Besides, Bahrudin et al. [9] proposed to display the content of picture captured from a webcam and uploaded the picture to a webpage when a sensor detected 
an occurrence of fire. Apart from that, according to [10], the simplest fire alarm system can be installed by using global system for mobile (GSM) network. However, those proposed fire alarm systems in [6-9] unable to inform Fire and Rescue Department at very first time to prevent fire from spreading. It is reported that in 2016, more than 6,000 buildings in Malaysia were damaged by fire annually and killed over 1,000 lives according to statistic from Fire and Rescue Department [11]. According to [12], even with the presence of smoke alarm, only $18.3 \%$ of alarm successfully alerted occupants. This indicates that the current automatic fire alarm system is not smart enough to reduce the fire disaster case. The occupants remain unknown that their house is on fire especially when they are away from their house. In addition, the delay of notification to rescue department may leads to fire quickly spread to other buildings. This is even more critical if the building on fire is a high rise building. Therefore, an automatic smoke detection system using Internet of Things (IoT) is proposed. The highlight of the system is the capability of system to notify the occupant as well as Fire and Rescue Department once the fire is detected. This can reduce the possibility of fire break out, protect people and properties.

\section{PROJECT DESIGN}

Automatic smoke detector by using IoT is proposed to monitor the smoke condition in a house where the user can access via Favoriot platform. In this project, Arduino Uno [13] is used as a microcontroller to control all the digital devices. Besides that, the ESP8266 WiFi shield [14] is used as a medium to interconnect devices with the network so that the data from the smoke sensor can be updated in the Favoriot platform. If the smoke detector senses any existence of smoke, it will transmits signal to the Arduino Uno and the alarm will be activated. At the same time Favoriot platform will display the updated status of smoke level and the notification will be sent to the Fire and Rescue Department if the fire is detected. Therefore, the Fire and Rescue Department will quickly heading to the scene. Figure 1 shows the block diagram of project design. The hardware component consists of gas (MQ-2) sensor [15], Arduino Uno, WiFi shield, buzzer, and resistor. For monitoring of purpose, Favouriot platform is used to support the integration of data from sensors and enable the user to collect and store the data in the platform as well as to monitor the reading of project.

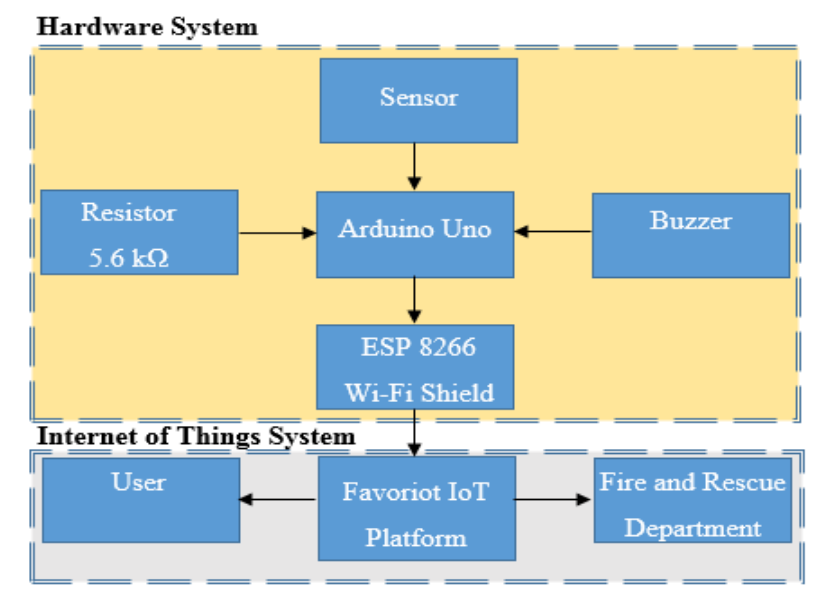

Figure 1. The block diagram of automatic fire alarm system

The design of product have been sketched by using Solidworks software to determine the height, width and radius of product. The product is printed using 3-dimension printer which made from Polylactic Acid (PLA) material as a base of designing product. It is light weight and therefore suitable for the product. Figure 2 shows the dimension of the design by using Solidworks. Figure 3 shows the back side of product with the radius for the MQ-2 sensor whereas Figure 4 shows the actual printed product. Once the product casing is ready, the components that are assembled in the casing is shown in Figure 5. The Arduino Uno R3 is installed in the casing with the WiFi Shield as a controller to operate the smoke sensor and sends the smoke level to the Favoriot platform. The $1.7 \mathrm{~cm}$ radius hole is used to install the smoke sensor so that it can senses the smoke easily. A calibration process must be done for the circuit with a buzzer and a $5.6 \mathrm{k} \Omega$, before it can be used to sense smoke level in a room. 


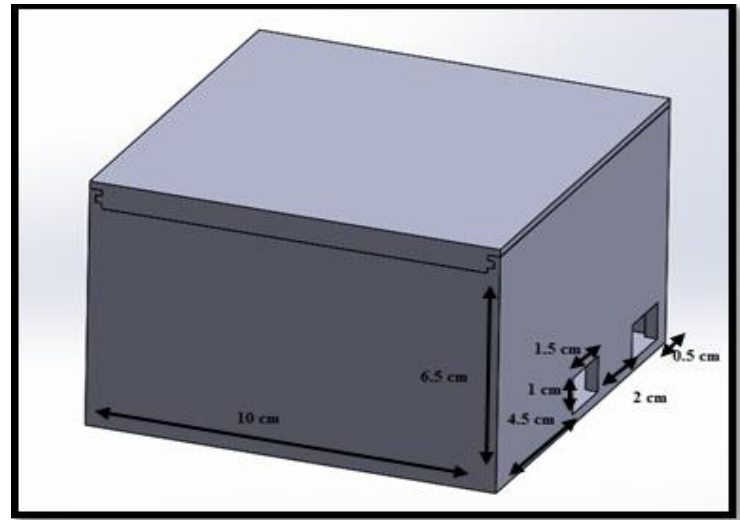

Figure 2. The dimension of casing design by using Solidworks
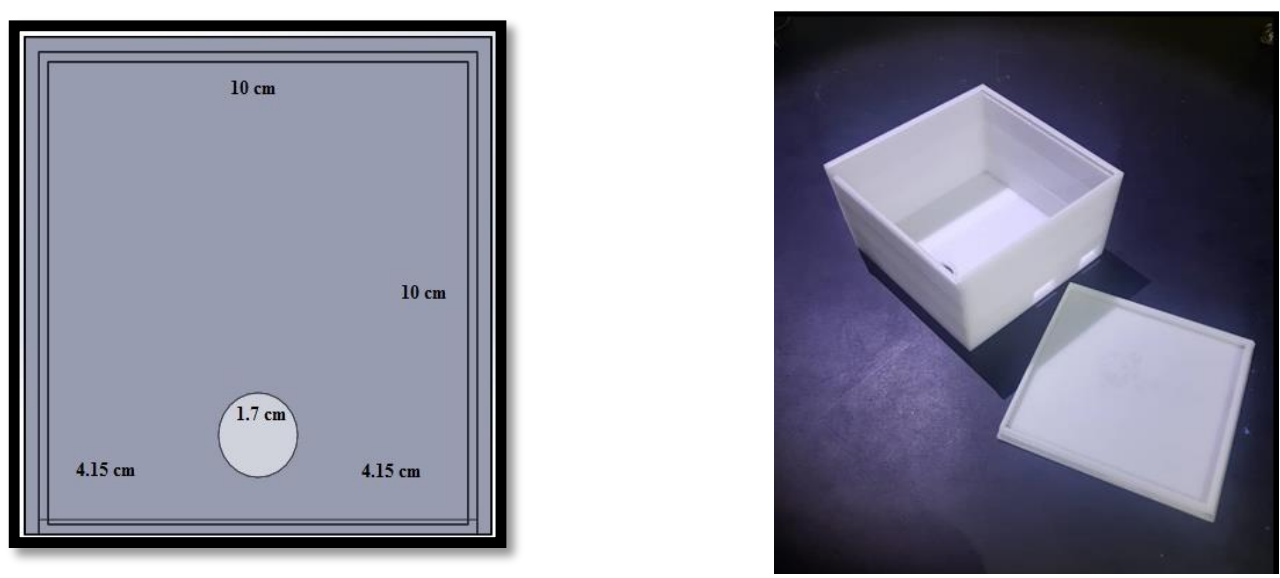

Figure 3. The dimension for back side of product for the installation of gas sensor.

Figure 4. The actual printed product

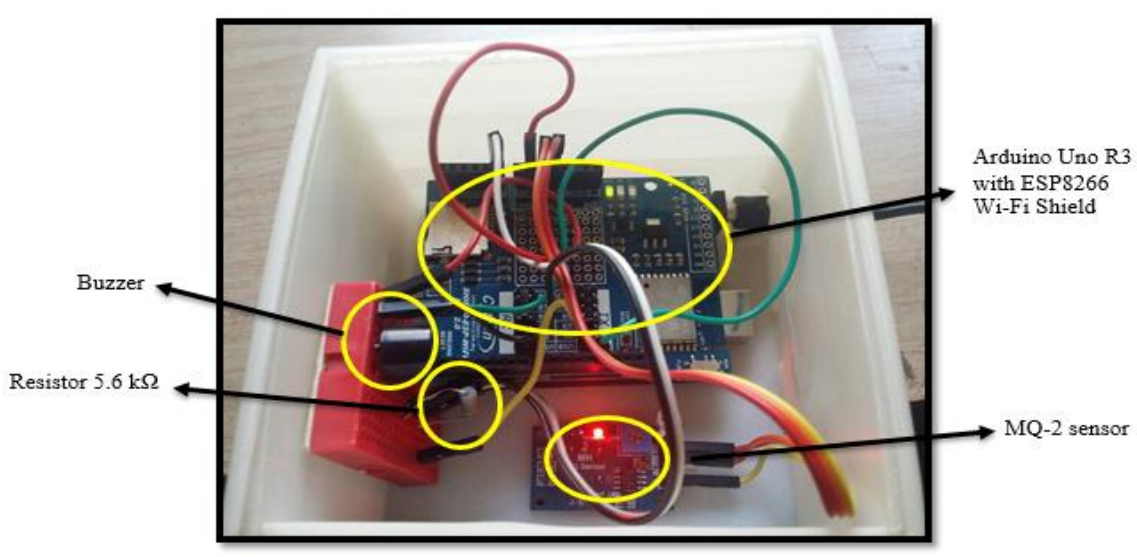

Figure 5. The components are assembled inside the casing

\subsection{Methodology}

The flow chart is shown in Figure 6. In a clear air condition, the system is used to monitor the smoke condition of a house/room. Initially, the automatic smoke detection system is in standby mode. The sensor keeps sensing the smoke level and update to Favoriot platform. Once the smoke is detected and exceeds the threshold level of 80 parts per million (ppm), alarm is activated in order to give warning to the occupant that 
the house might be on fire. At the same time, warning message with personal details is sent to the user and Fire and Rescue Department. This is to alert the user especially when they are away from their house. Early notification message enable user to call their family at home to take any fire escape plan. The highlight of this project is the system able to notify the fire department at the first time. It is important that firefighter arrive to the scene at the very first time to extinguish the fire.

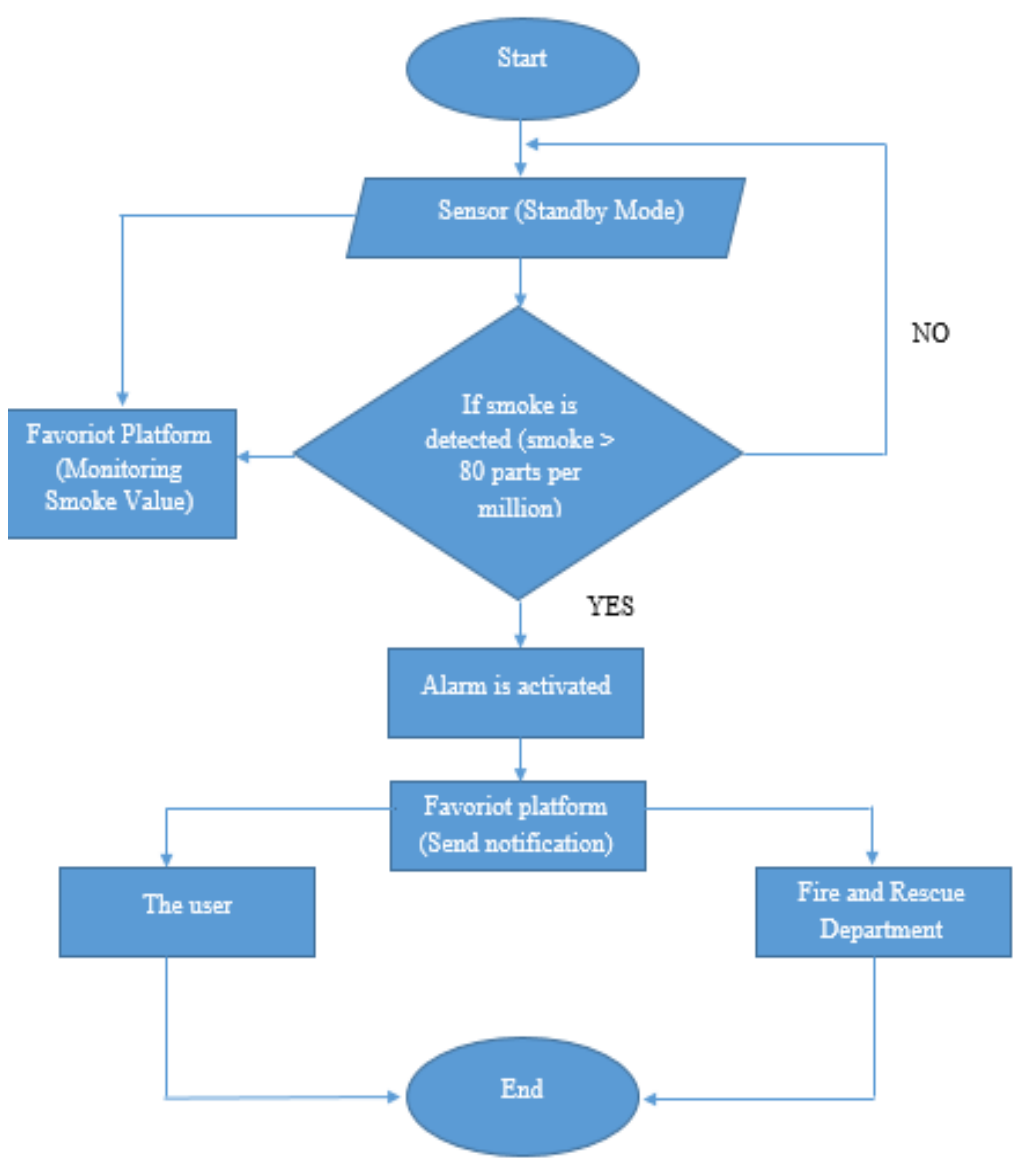

Figure 6. The flowchart of the project

\subsection{Testing Materials}

Accoding to [16], paper material can ignite easily. Once they have caught the fire, frames may rapidly spread to other materials and would be hard to extinguish. To this aim, the smoke detector is tested by using materials such as paper, box fragment and silky fiber. It is because these materials are easily found in the room and considered as a flammable material. Therefore, the time taken for smoke detector to detect the presence of smoke is recorded. Table 1 shows the different materials tested in a room for two threshold values.

Table 1. The different matrials to be tested in a room

\begin{tabular}{cc}
\hline Material & Threshold value $(\mathrm{ppm})$ \\
\hline Paper & 80 and 100 \\
Box & 80 and 100 \\
Silky fiber & 80 and 100 \\
\hline
\end{tabular}

\section{RESULTS}

The automatic smoke detection system have been tested at a room in the village house to simulate real room environment and the room is equipped with 4 Mbps TM Streamyx of internet connection. A room in a normal condition (without existence of smoke), the smoke level is less than $5 \mathrm{ppm}$ which depends on the MQ2 sensor sensitivity in clean air factor resistance. The smoke value starting from 50 to $80 \mathrm{ppm}$ can be defined

Automatic smoke detection system with favoriot platform using internet of .... (Mohd Alif bin Suparman) 
as lower smoke presence. Therefore, the threshold level has been selected for this experiment is $80 \mathrm{ppm}$ and $100 \mathrm{ppm}$ to measure how fast the MQ-2 smoke sensor can senses and activate the buzzer. In additional, the value of $80 \mathrm{ppm}$ and $100 \mathrm{ppm}$ can caused to cough, sore eyes and hard breathing. Table 2 shows the experimental result collected from three burning materials (paper, box and silky fiber).

Table 2. The results collected from the experiment

\begin{tabular}{ccccc}
\hline Material & Time Set & Achieved Value $(\mathrm{ppm})$ & Threshold Value $(\mathrm{ppm})$ & Buzzer (On/Off) \\
\hline Paper & $60 \mathrm{~s}$ & 88 & 80 & On \\
Box & $60 \mathrm{~s}$ & 86 & 80 & On \\
Silky fiber & $60 \mathrm{~s}$ & 59 & 80 & Off \\
Paper & $120 \mathrm{~s}$ & 104 & 100 & On \\
Box & $120 \mathrm{~s}$ & 98 & 100 & Off \\
Silky fiber & $120 \mathrm{~s}$ & 78 & 100 & Off \\
\hline
\end{tabular}

According to the Table 2, the achieved value higher than the threshold value which indicates that the buzzer is activated and the notification is sent to the user and Fire and Rescue Department as a warning alarm. Three materials are used to ensure ability of the MQ-2 sensor senses the smoke and the comparison in term of time is recorded. The result shows the time taken and the achieved value in ppm for both threshold values. The paper and box materials take less than 1 minute to activate the alarm system at threshold level of $80 \mathrm{ppm}$, faster than the threshold level of $100 \mathrm{ppm}$. At the same time, in 1 minute, burning of silky fiber material causes to 59 ppm fire smoke level, and this will not activate the alarm, as the threshold level is set at $80 \mathrm{ppm}$. Similarly, for $100 \mathrm{ppm}$ threshold, within a period of 2 minutes, a total of $78 \mathrm{ppm}$ smoke level is recorded; this will not activate the alarm too. Alarm is activated only when the achieved value is higher than the threshold value.

Based on the experiment in testing room, the lower the threshold level, the faster the smoke level reached at threshold level to alert the user via Favoriot platform and notified the Fire and Rescue Department to take preliminary action. In additional, smoke levels that more than $80 \mathrm{ppm}$ may cause to sore eyes, cough and hard breathing that can bring to death. Therefore, the best threshold level is at $80 \mathrm{ppm}$ to avoid high concentrations of smoke filling up the room and residences have enough time to skip from a burning house. Once the smoke level exceeds the threshold value, the user and Fire and Rescue Department will receive a warning message as shown in Figure 7 and Figure 8, respectively via Favoriot platform. The notification message to Fire and Rescue Department includes all the details such as permanent address, name of owner, and telephone number in order for Fire and Rescue Department to make confirmation and heading to the scene.

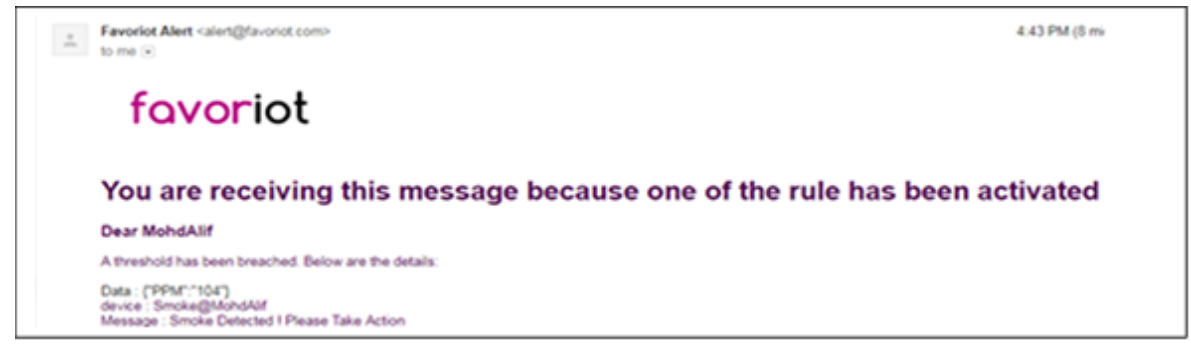

Figure 7. The notification message received by the user via Favoriot platform

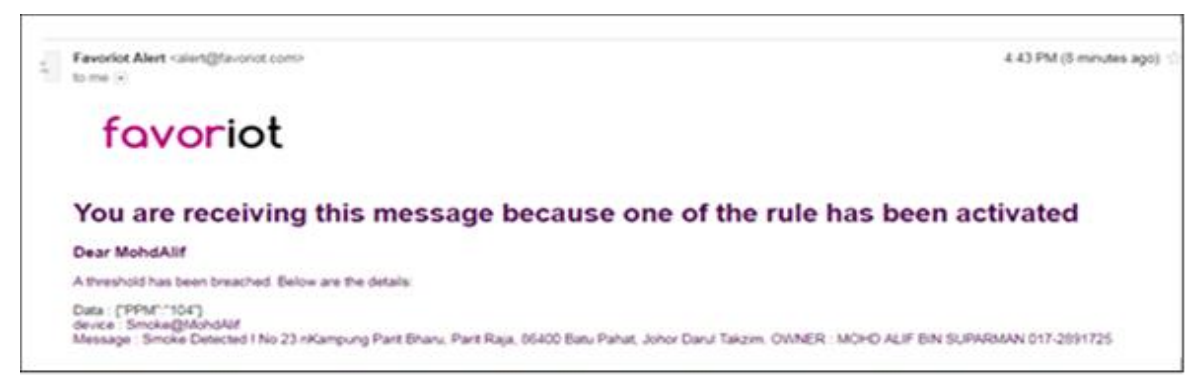

Figure 8. The notification message received by Fire and Rescue Department via Favoriot platform 


\section{CONCLUSION}

Automatic smoke detector using IoT allows the user to monitor the room's smoke condition whenever they are far away from their house through the Favoriot platform by using personal computer, laptop or mobile phone. All the data are recorded in data stream through Internet of Things medium. Once the fire is detected, the notification message will be sent to the Fire and Rescue Department to request for rescue action. To this aim, the suggestion of threshold value for the automatic smoke detector is set to $80 \mathrm{ppm}$ in which it takes less than one minute to alert the house owner before the fire starts burning out while the house owners are far away from their house. The implementation of Internet of Things in the product system gives advantages in term of safety, ability to react, and cost effective. Besides that, Internet of Things able to operate anytime with the network connection to record all the data in Favoriot platform. The user can monitor anywhere and anytime whenever they are far away from their house. Such product not only used to detect the present of smoke but also used for prevention against fire outbreak.

In future, it is recommended the automatic smoke detector with Favoriot platform can be improvised using future technology such as remote control sensor so that the user able to monitor easily without access to the Favoriot platform. In additional, it would be good if the user can adjust the sensitivity of sensor and threshold value without program it.

\section{ACKNOWLEDGEMENTS}

The authors are grateful to UTHM funded under "Tier 1 Grant" Vot No. H262 for supporting the expenses to this paper.

\section{REFERENCES}

[1] M. Hefeeda and M. Bagheri, "Efficient K-coverage Algorithms for Wireless Sensor Networks and Their Applications to Early Detection of Forest Fires," M.Sc. thesis, Simon Fraser University, pp. 1-7, 2007.

[2] S. Gupta, et al., "Design and Development of Automatic Fire Alert System," 2016 8th International Conference on Computational Intelligence and Communication Networks, pp. 632-636, Dec 2016.

[3] M. D. Stephenson, “Automatic Fire-Detection Systems," International Journal of Electronics \& Power, vol. 31, pp. 239-243, Mar 1985.

[4] H. Azmi, N. A. Shuaib, M. F. Ghazali, Z. Shayfull and M. Z. M. Zain, "Fire Alarm System, Portable Fire Extinguisher and Hose Real System Maintenances for Satefy Purpose and Requirement," National Symposium on Advancement in Ergonomics and Safety (ERGOSYM), pp. 184-197, 1-2 Dec. 2009.

[5] Fixed fireflighting system-Automatic sprinkler system-design, installation and maintenance. Department of Standards Malaysia, 2006.

[6] Fire protection-general product catalog.” Safer Smarter Tyco. pp.1-100.

[7] V. Rajput, et al., "Low Cost Fire Alarm System with Sprinkler," International Journal of Advanced Research in Computer Science, vol. 8, pp. 607-609, May 2017.

[8] M. M. Hasan and M. A. Razzak, "An Automatic Fire Detection and Warning System under Home Video Surveillance," 2016 IEEE 12th International Colloqium on Signal Processing and its Application (CSPA 2016), pp. 258-262, Mar 2016.

[9] M. S. Bahrudin, et al., "Development of Fire alarm system using Raspberry Pi and Arduino Uno," 2013 International Conference on Electrical, Electronic and System Engineering (ICEESE 2013), pp. 43-48, Dec 2013.

[10] S. Suresh, "Home Based Fire Monitoring and Warning System," 2016 International Conference on ICT in Business Industry \& Government (ICTBIG), pp. 1-6, Nov 2016.

[11] https://www.nst.com.my/news/2016/09/176607/about-6000-premises-destroyed-fire-annually-malaysia [Accessed Online: 07 November 2017]

[12] “Residential Building Electrical Fires (2014-2016)," Topical Fire Report Series, vol. 19 (8), pp. 1-14, Dec. 2018.

[13] https://components101.com/microcontrollers/arduino-uno [Accessed Online: 28 Feb. 2018]

[14] Cytron Technologies, “ESP WiFi Shield-user manual Rev-2.0,"pp. 1-17, April 2016.

[15] https://components101.com/mq2-gas-sensor [Accessed Online: 8 Jan. 2018]

[16] HSE, "Paper mills: Guidance on fire risk," Health and Safety Executive, pp. 1-41, Feb. 2006. 


\section{BIOGRAPHIES OF AUTHORS}

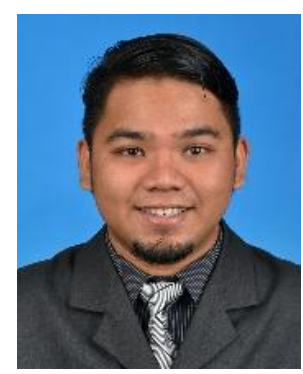

Mohd Alif received his Diploma in Electronic Engineering Communication from Polytechnic Sultan Salahuddin Abdul Aziz Shah, Shah Alam in 2013. Next, he continues his Bachelor degree in Electronic Engineering (Communication) from University Tun Hussein Onn Malaysia and graduated in 2018. In 2013, he successfully created a corn seed separator machine for Final Year Project (FYP) in close collaboration with Department of Mechanical Engineering. After graduated as Diploma's holder, he joined facilities management company in Audio Visual Engineering to obtain his working experience for one year before he continues his Bachelor degree in 2014. From 2014 to 2018, he acquired his knowledge in electronic communication engineering field through various subjects at the university and used the experience to create the safety equipment by using Internet of Things (IoT). In addition, he earned a suggestion in operating building control equipment system from Fire and Rescue Department. In the meantime, he is a graduated engineer of Board of Engineers Malaysia (BEM).

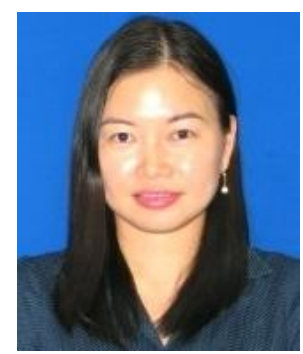

Siat Ling Jong received her Bachelor degree in Electrical Engineering from Universiti Tun Hussein onn Malaysia in 2007. After that she obtained scholarship to pursue her Master and Doctorate degree in Electrical and Communication Engineering in the field of radio wave propagation for satellite communication system in Universiti Teknologi Malaysia in 2009 and 2015, respectively. In 2007, she joined Universiti Tun Hussein Onn Malaysia as an assistant lecturer. In 2012 and 2013, she obtained research attachment grant to Politecnico di Milano, Milan, Italy to do her research on rain effects and fade dynamics on satellite communication links. In 2014, she obtained Young Scientist award in URSI General Assembly and Scientific Symposium. Since 2015, she is a lecturer of Electronic Communications at Universiti Tun Hussein Onn Malaysia. Her research interests include IoT, rain attenuation, radio wave propagation for satellite communication system and atmospheric science. Since July 2015, she involves in an experimental activity of a Ka-band propagation measurement campaign in close collaboration with European Space Agency (ESA), Joanneum Research (Austria) and Universiti Teknologi Malaysia. Currently, she is member of Institute of Electrical and Electronics Engineers (IEEE) and Board of Engineers Malaysia (BEM). 